\title{
Game On. . Girls: Associations Between Co-playing Video Games and Adolescent Behavioral and Family Outcomes
}

\author{
Sarah M. Coyne \\ Laura M. Padilla-Walker \\ Brigham Young University, laura_walker@byu.edu \\ Laura Stockdale \\ Randal D. Day
}

Follow this and additional works at: https://scholarsarchive.byu.edu/facpub

Part of the Social and Behavioral Sciences Commons

\section{Original Publication Citation}

Coyne, S. M., Padilla-Walker, L. M., *Stockdale, L., \& Day, R. D. (2011). Game On... Girls:

Associations Between Co-playing Video Games and Adolescent Behavioral and Family Outcomes . Journal of Adolescent Health, 49, 160-165.

\section{BYU ScholarsArchive Citation}

Coyne, Sarah M.; Padilla-Walker, Laura M.; Stockdale, Laura; and Day, Randal D., "Game On. . Girls: Associations Between Co-playing Video Games and Adolescent Behavioral and Family Outcomes" (2011). Faculty Publications. 4930.

https://scholarsarchive.byu.edu/facpub/4930

This Peer-Reviewed Article is brought to you for free and open access by BYU ScholarsArchive. It has been accepted for inclusion in Faculty Publications by an authorized administrator of BYU ScholarsArchive. For more information, please contact ellen_amatangelo@byu.edu. 
Original article

\title{
Game On... Girls: Associations Between Co-playing Video Games and Adolescent Behavioral and Family Outcomes
}

\author{
Sarah M. Coyne, Ph.D.*, Laura M. Padilla-Walker, Ph.D., Laura Stockdale, and Randal D. Day, Ph.D. \\ School of Family Life, Brigham Young University, Provo, Utah
}

Article history: Received June 14, 2010; Accepted November 15, 2010

Key words: Video games; Co-play; Mediation; Adolescents; Gender; Prosocial; Computer games

\section{A B S T R A C T}

Purpose: Video game use has been associated with several behavioral and health outcomes for adolescents. The aim of the current study was to assess the relationship between parental co-play of video games and behavioral and family outcomes.

Method: Participants consisted of 287 adolescents and their parents who completed a number of video game-, behavioral-, and family-related questionnaires as part of a wider study. Most constructs included child, mother, and father reports.

Results: At the bivariate level, time spent playing video games was associated with several negative outcomes, including heightened internalizing and aggressive behavior and lowered prosocial behavior. However, co-playing video games with parents was associated with decreased levels of internalizing and aggressive behaviors, and heightened prosocial behavior for girls only. Co-playing video games was also marginally related to parent-child connectedness for girls, even after controlling for age-inappropriate games played with parents.

Conclusions: This is the first study to show positive associations for co-playing video games between girls and their parents.

(C) 2011 Society for Adolescent Health and Medicine. All rights reserved.

Adolescents are said to live in a "media saturated world," spending more time with the media than they do in school [1]. Video games represent one type of media that is becoming increasingly popular among adolescents. A recent study by the Kaiser Family Foundation [1] found that adolescents reported playing video games for about an hour each day, a rate that has nearly tripled over the last decade. On the whole, boys reported playing more video games than girls. The study also found that although many adolescents reported playing age-appropriate, relatively violent-free games, about half the sample (and 70\% of boy gamers) reported playing violent and controversial games (e.g., Grand Theft Auto), at least occasionally. This confirms a growing body of research that shows that boys generally play

\footnotetext{
* Address correspondence to: Sarah M. Coyne, Ph.D., School of Family Life Brigham Young University, JFSB 2087, Provo, UT 84602.

E-mail address: smcoyne@byu.edu
}

age-inappropriate video games more often and more intensely than girls [2,3].

Much research has shown that playing video games can be problematic for some youth. For example, Anderson et al [4] found that children who spent more time playing video games achieved lower grades over the course of the school year as compared with their peers who played less frequently. These children also showed more aggressive impulses and were more likely to infer hostile intent when none existed. This in turn was related to heightened levels of aggressive behavior. Other research has found that adolescents who were "addicted" to video games showed a variety of psychosocial and health problems [5].

Given these effects, it is not surprising that parents are most concerned with games interfering with schoolwork, social skills, and exercise [6]. Parents are also concerned with violent content in video games, but less so than the actual time spent by the adolescent in playing them. Accordingly, parents deal with video games in a variety of ways. There are generally three mediation 
strategies that parents use for video game play. Restrictive mediation is the most common strategy, and it involves parents placing rigid guidelines and rules on video game use and content $[6,7]$. Active mediation involves asking children questions about questionable content of video games. Generally, parents who use these first two types of mediation strategies are more worried about the negative effects of video games [8]. Finally, co-viewing or co-playing, involves parents playing the video games with their child.

The American Academy of Pediatrics Council on Communications and Media has suggested that co-viewing is one way by which parents can decrease negative media effects on their children [9]. However, there have been mixed results regarding the successfulness of co-playing (and co-viewing) as a parental mediation strategy. Some research has found positive effects of co-viewing. For example, co-viewing with parents enhanced learning strategies among preschool children [10] and co-viewing scary movies with an older sibling decreased fear responses [11]. However, Nathanson [12,13] found that there are often unintended effects of co-viewing television with children. While co-viewing, children may assume that parents condone what the child is viewing, even endorsing the negative content viewed.

Although several studies have examined co-viewing in a television context, to our knowledge, research has not examined the effects of co-playing video games. In fact, our literature search only revealed two studies that had explicitly focused on coplaying as a parental mediation strategy, both of which focused on predictors of co-playing as opposed to outcomes. It seems that parents who play video games with their children have different motives as compared with parents who use other mediation strategies. Nikken et al $[7,8]$ have found that parents who coplay are more likely to expect positive social and emotional effects of gaming for their children and are more likely to enjoy playing video games themselves. Whether or not co-playing actually results in any positive outcome for children is yet to be revealed. Co-playing is arguably more active than co-viewing, as parents must actively take part in the video game play. Coviewing requires almost no parental effort, whereas co-playing of video games requires knowledge of the game, a certain skill level, and may represent the active efforts of the parent to become engaged and involved. This may send the message that parents want to be involved with their adolescent's activities and may increase feelings of connectedness between the adolescent and parent. By contrast, co-playing may enhance negative effects of playing video games because parents may inadvertently endorse both the time spent by the adolescent in playing and the content they are exposed to during co-play $[12,13]$. Thus, the current study will examine potential positive and negative outcomes of co-playing video games during adolescence. The following hypotheses will guide the study:

- H1: Given the active nature of co-playing, we predict that higher levels of co-playing (particularly age-appropriate games) will be associated with higher levels of family connectedness.

- H2: We expect that co-playing age-appropriate video games will either be unrelated or negatively related to aggression, delinquency, and internalizing behavior, and positively related to prosocial behavior. Conversely, co-playing age-inappropriate video games may augment negative effects of playing, leading to increased aggression, delinquency, internalizing behavior, and decreased levels of prosocial behavior.

\section{Methods}

\section{Participants and procedures}

The participants for this study were recruited from the Flourishing Families Project. The project is an ongoing study of inner family life, and the current sample involved families with a child between the ages of 11 and 16 years (mean age of the child = 13.26, SD = 1.05). Participants for the Flourishing Families Project were randomly selected from a large northwestern city based on whether they had a child between the ages of 11 and 14 years in the home. Families were interviewed in their homes, with each interview consisting of a video task (not reported here) and questionnaires completed by the child, mother, and father, which included numerous questions about family processes and adolescent behaviors. Our overall response rate of eligible families was $61 \%$ (for more information on the procedures see [14]).

Participants included 287 families (106 single parent and 190 two-parent, 65\% male adolescents) who were selected from a larger sample $(\mathrm{N}=465)$. Families were selected for the current study only if the adolescent child reported playing video games. Regarding ethnicity, 67\% of families were European American, $12 \%$ were African American, and 21\% were multiethnic. In all, 39\% of fathers and $34 \%$ of mothers reported having at least a bachelor's degree. Moreover, $96 \%$ of fathers and $63 \%$ of mothers reported being currently married (never divorced). Among the rest, $10 \%$ of mothers were single parents, never married; $3 \%$ were separated; $15 \%$ were divorced; $5 \%$ were cohabiting; and $2 \%$ were widowed.

\section{Measures}

Controls. To assess the age-inappropriateness of the games being played, adolescents responded to one item asking what games they typically played with their parents. These games were then coded as 0 (age-appropriate; games with ratings of $\mathrm{T}$ or below) or 1 (age-inappropriate; games rated $M$ ). To assess the overall time spent on playing video games, adolescents responded to one item asking how many hours they spend in a typical day playing video games. Response categories ranged from 1 (none) to 9 (more than 8 hours).

\section{Co-playing}

Adolescents responded to one item asking how they used media or technology to connect with their parents ("How often do you play video games with your parent?") on a scale ranging from 1 (never) to 6 (more than once a day). This item was based on research by Nikken et al [7,8], although the scale has been expanded from its original form.

\section{Internalizing and delinquency}

Internalizing behaviors and delinquency were measured with items assessing depression/anxiety (13 items) and delinquency (nine items), which have shown adequate validity and reliability 
in adolescent samples [15]. Sample items for internalizing include "I am unhappy, sad, or depressed"; whereas, for delinquency, "I lie or cheat." Adolescents were the only reporters of their own internalizing behavior $(\alpha=.85)$, but mothers $(\alpha=.77$, factor loading $=.91)$, fathers $(\alpha=.59$, factor loading $=.97)$, and adolescents $(\alpha=.75$, factor loading $=.74)$ answered the delinquency items with regard to the adolescents' behavior on a scale ranging from 1 (not true) to 3 (very true or often true). Mean scale scores from all three respondents were used to create a latent variable representing adolescent delinquency.

\section{Aggression}

Adolescents' aggressive behavior was assessed using items taken from the self-restraint dimension of Weinberger et al [16] aggressive behavior measure. Mothers $(\alpha=.88$, factor loading $=$ $.54)$, fathers $(\alpha=.83$, factor loading $=.50)$, and adolescents $(\alpha=$ .88 , factor loading $=.44$ ) rated how well each of the five items described the adolescent based on a 5-point Likert scale ranging from 1 (does not describe me/my child) to 5 (describes me/my child very well). Sample items include "if someone tries to hurt me, I make sure I get even with them" and "I lose my temper and 'let people have it' when I'm angry." Mean scale scores from all three respondents were used to create a latent variable representing adolescent aggression.

\section{Prosocial behavior}

Adolescents' prosocial behavior toward family members was measured using a modified version of the Kindness and Generosity subscale of the Values in Action Inventory of Strengths [17]. The original measure was designed to assess behavior toward strangers, and the current study adapted these items to target prosocial behavior toward family members (nine items, e.g., "I really enjoy doing small favors for my family") on a 5-point Likert scale ranging from 1 (not like me/my child at all) to 5 (very much like $\mathrm{me} / \mathrm{my}$ child). Mothers ( $\alpha=.90$, factor loading $=.68$ ), fathers $(\alpha=.91$, factor loading $=.72$ ), and adolescents $(\alpha=.91$, factor loading $=.77$ for girls, .48 for boys) reported on the adolescents' prosocial behavior toward family members, and mean scale scores were used to create a latent variable representing prosocial behavior toward family.

\section{Parent-child connection}

Mothers' and fathers' connection to the adolescent child was measured using the warmth/connection subscale from the Parenting Styles and Dimensions Questionnaire-Short Version [18]. Mothers, fathers, and adolescents were asked how often they/ their parent(s) displayed certain behavioral characteristics of connection such as "My parent is responsive to my feelings and needs/ I am responsive to my child's feelings and needs." Responses ranged on a 5-point Likert-type scale from 1 (never) to 5 (always), with higher scores indicating higher levels of maternal and paternal connection. Mean scale scores from mother- $(\alpha=$ .78 , factor loading $=.44)$, father- $(\alpha=.79$, factor loading $=.46)$, and adolescent-report of both mother $(\alpha=.84$, factor loading $=$ $.77)$ and father $(\alpha=.84$, factor loading $=.84)$ were used to create a latent variable representing parental connection.

\section{Results}

\section{Descriptive statistics, gender differences, and correlations}

Means, standard deviations, and ranges for all study variables are presented in Table 1. Although child-reported means of coplaying were relatively low and did not differ as a function of child gender, $45 \%$ of boys and $54 \%$ of girls reported that their parents played video games with them to some degree. In all, $31 \%$ of adolescents reported playing age-inappropriate games with their parents ( $42 \%$ of boys, $15 \%$ of girls), and this was used as a control variable in the final analysis. The three most frequently played games by parents and their sons were Call of Duty (Infinity Ward, Encino, CA), Wii Sports (Nintendo, Kyoto, Japan), and Halo (Bungie, Chicago, IL). Comparatively, the three top games played by daughters and their parents were Mario Kart/Mario Brothers (Nintendo, Kyoto, Japan), Wii Sports (Nintendo, Kyoto, Japan), and Rock Band/Guitar Hero (Harmonix Music Systems, Cambridge, MA).

Several univariate analyses of variance were conducted to determine whether co-playing differed as a function of family structure or ethnicity, and they were not statistically significant. Further, correlations revealed that co-playing was not related significantly to family income, but was related negatively to mothers' age $(r=-.17, p<.01$; there was no significant correlation with fathers' age). Analyses of variance were also conducted to determine whether study variables differed as a function of gender of the adolescent, and results revealed that age-inappropriate games, video game use, internalizing, child-reported delinquency, and mother- and child-reported prosocial behaviors differed as a function of gender, with boys more likely to play age-inappropriate games as well as have higher video game use and delinquency; and girls having higher levels of internalizing problems and prosocial behaviors (Table 1).

Bivariate correlations for all study variables are presented in Table 2, separately for boys and girls. Most notably, there were no significant correlations between boys' reports of co-playing and outcome variables, but girls' reports of co-playing were associated negatively with internalizing, mother- and father-reported aggression, and father-reported delinquency, and positively with all reports of prosocial behavior and connection (with the exception of father-reported connection).

\section{Measurement model}

Using Analysis of Moments Structure software (Amos Development Cooperation \& SPSS Inc.) [19], a measurement model was estimated including latent constructs for aggression, delinquency, prosocial behavior, and connection. To test for group differences as a function of gender of the child, multigroup models were estimated and compared using $\chi 2$ difference tests. Factor loadings were examined by comparing a model where factor loadings were constrained to be equal across gender to a model where paths were free to vary across gender. Comparing the fully constrained model with the fully unconstrained model resulted in a significant decrease in model fit $\left(\chi^{2}\right.$ difference $(9)=17.83, p$ $<.05$ ), suggesting measurement variance of the factor loadings as a function of child gender. By constraining paths to be equal one at a time, it was determined that factor loadings on the child's report of prosocial behavior loaded higher for girls (.77) than for boys (.48). Thus, the final measurement model was estimated by constraining all factor loadings to be equal across 
Table 1

Descriptive statistics and gender differences on all study variables

\begin{tabular}{|c|c|c|c|c|}
\hline \multirow[t]{2}{*}{ Variables } & \multicolumn{4}{|l|}{ M (SD) Range } \\
\hline & Total sample $n=287$ & Boys $n=186$ & Girls n $=101$ & $F$ value \\
\hline \multirow[t]{2}{*}{ Age-inappropriate games } & $1.33(.47)$ & $1.43(.50)$ & $1.15(.36)$ & $10.74^{* * *}$ \\
\hline & $1.00-2.00$ & $1.00-2.00$ & $1.00-2.00$ & \\
\hline \multirow[t]{2}{*}{ Video game use } & $3.41(1.62)$ & $3.72(1.73)$ & $2.85(1.20)$ & $20.12^{* * *}$ \\
\hline & $2.00-9.00$ & $2.00-9.00$ & $2.00-7.00$ & \\
\hline \multirow[t]{2}{*}{ Co-playing } & $1.92(1.19)$ & $1.84(1.17)$ & $2.07(1.22)$ & 2.35 \\
\hline & $1.00-6.00$ & $1.00-6.00$ & $1.00-6.00$ & \\
\hline \multirow[t]{2}{*}{ Internalizing } & $1.34(.33)$ & $1.29(.33)$ & $1.43(.33)$ & $10.49^{* * *}$ \\
\hline & $1.00-2.92$ & $1.00-2.92$ & $1.00-2.46$ & \\
\hline \multirow{2}{*}{ Aggression MR } & $1.72(.82)$ & $1.66(.74)$ & $1.81(.96)$ & 2.07 \\
\hline & $1.00-5.00$ & $1.00-4.20$ & $1.00-5.00$ & \\
\hline \multirow[t]{2}{*}{ Aggression FR } & $1.70(.66)$ & $1.67(.60)$ & $1.77(.77)$ & .98 \\
\hline & $1.00-4.20$ & $1.00-3.80$ & $1.00-4.20$ & \\
\hline \multirow[t]{2}{*}{ Aggression CR } & $2.16(.92)$ & $2.15(.91)$ & $2.19(.95)$ & .14 \\
\hline & $1.00-5.00$ & $1.00-5.00$ & $1.00-5.00$ & \\
\hline \multirow[t]{2}{*}{ Delinquency MR } & $.15(.23)$ & $.17(.23)$ & $.12(.23)$ & 2.98 \\
\hline & $.00-1.44$ & $.00-1.44$ & $00-1.11$ & \\
\hline \multirow[t]{2}{*}{ Delinquency FR } & $.09(.14)$ & $.10(.14)$ & $.07(.14)$ & .11 \\
\hline & $.00-.89$ & $.00-.67$ & $.00-.89$ & \\
\hline \multirow[t]{2}{*}{ Delinquency CR } & $1.20(.25)$ & $1.22(.26)$ & $1.16(.22)$ & $3.91^{*}$ \\
\hline & $1.00-2.78$ & $1.00-2.78$ & $1.00-2.11$ & \\
\hline \multirow[t]{2}{*}{ Prosocial MR } & $3.37(.75)$ & $3.27(.74)$ & $3.56(.73)$ & $10.24^{* * *}$ \\
\hline & $1.33-4.67$ & $1.33-4.67$ & $1.78-4.67$ & \\
\hline \multirow[t]{2}{*}{ Prosocial FR } & $3.38(.79)$ & $3.32(.78)$ & $3.51(.82)$ & 2.21 \\
\hline & $1.11-5.00$ & $1.33-4.89$ & $1.11-5.00$ & \\
\hline \multirow[t]{2}{*}{ Prosocial CR } & $3.98(.83)$ & $3.86(.83)$ & $4.19(.77)$ & $10.46^{* * *}$ \\
\hline & $1.63-5.00$ & $1.63-5.00$ & $1.63-5.00$ & \\
\hline \multirow[t]{2}{*}{ Connection MR } & $4.27(.52)$ & $4.28(.47)$ & $4.25(.59)$ & .21 \\
\hline & $2.20-5.00$ & $2.60-5.00$ & $2.20-5.00$ & \\
\hline \multirow[t]{2}{*}{ Connection FR } & $3.86(.58)$ & $3.83(.56)$ & $3.91(.61)$ & .72 \\
\hline & $2.20-5.00$ & $2.40-5.00$ & $2.20-5.00$ & \\
\hline \multirow[t]{2}{*}{ Connection CRM } & $3.79(.83)$ & $3.75(.83)$ & $3.86(.81)$ & 1.26 \\
\hline & $1.00-5.00$ & $1.00-5.00$ & $1.80-5.00$ & \\
\hline \multirow[t]{2}{*}{ Connection CRF } & $3.62(.87)$ & $3.57(.90)$ & $3.72(.82)$ & 1.65 \\
\hline & $1.00-5.00$ & $1.00-5.00$ & $1.60-5.00$ & \\
\hline
\end{tabular}

$\mathrm{MR}=$ mother report; $\mathrm{FR}=$ father report; $\mathrm{CR}=$ child report; $\mathrm{CRM}=$ child report of mother; $\mathrm{CRF}=$ child report of father.

$* p<.05$,

$* * p<.01$,

*** $p<.001$.

Table 2

Correlations between all study variables

\begin{tabular}{|c|c|c|c|c|c|c|c|c|c|c|c|c|c|c|c|c|c|}
\hline Study variables & 1 & 2 & 3 & 4 & 5 & 6 & 7 & 8 & 9 & 10 & 11 & 12 & 13 & 14 & 15 & 16 & 17 \\
\hline Age-inappropriate & - & .09 & .05 & $.34^{*}$ & -.14 & -.18 & .10 & .09 & -.07 & .02 & -.02 & -.06 & -.04 & .07 & .05 & -.06 & -.09 \\
\hline Video game use & .05 & - & .04 & .17 & -.14 & -.08 & $.21^{*}$ & .05 & .07 & .15 & .09 & .07 & .01 & -.01 & .14 & -.04 & .04 \\
\hline Co-playing & -.04 & $.24^{* * *}$ & - & $-.19^{*}$ & $-.25^{* *}$ & $-.31^{* *}$ & -.09 & -.01 & $-.26^{*}$ & -.10 & $.26^{* *}$ & $.34^{* *}$ & $.21^{*}$ & $.22 *$ & $.25^{*}$ & .18 & $.23^{*}$ \\
\hline Internalizing & .00 & $.15^{*}$ & -.02 & - & .17 & .10 & $.41^{* * *}$ & $.22^{*}$ & .01 & $.48^{* * *}$ & .01 & .02 & -.19 & -.03 & -.18 & $-.29 * *$ & $-.35^{* * *}$ \\
\hline Aggression MR & .10 & -.01 & .07 & .04 & - & $.69^{* * *}$ & $.31^{* * *}$ & $.45^{* * *}$ & .23 & $.38^{* * *}$ & $-.43^{* * *}$ & $-.31^{*}$ & $-.35^{* * *}$ & $-.26^{* *}$ & .02 & $-.32 * * *$ & $-.38^{* * *}$ \\
\hline Aggression FR & -.11 & .05 & .14 & .02 & $.55^{* * *}$ & - & .15 & $.28^{*}$ & $.33^{* *}$ & .17 & $-.51^{* * *}$ & $-.40^{* *}$ & $-.32^{* *}$ & -.23 & -.09 & -.17 & -.27 \\
\hline Aggression CR & .16 & .12 & .03 & $.39^{* * *}$ & $.40^{* * *}$ & $.28^{* *}$ & - & $.45^{* * *}$ & $.30^{*}$ & $.49^{* * *}$ & -.04 & -.15 & $-.20^{*}$ & -.11 & -.21 & $-.39 * * *$ & $-.23^{*}$ \\
\hline Delinquency MR & .05 & .07 & -.07 & .02 & $.55^{* * *}$ & $.29^{* * *}$ & $.25^{* * *}$ & - & $.80^{* * *}$ & $.73^{* * *}$ & $-.20^{*}$ & $-.30^{*}$ & $-.30^{* *}$ & -.05 & .01 & $-.21^{*}$ & -.19 \\
\hline Delinquency FR & .05 & .17 & .11 & -.04 & $.32^{* * *}$ & $.36^{* * *}$ & $.26^{* *}$ & $.63^{* * *}$ & - & $.58^{* * *}$ & -.22 & $-.44^{* * *}$ & $-.33^{* *}$ & -.09 & -.21 & -.07 & -.10 \\
\hline Delinquency CR & $.22^{\dagger}$ & $.15^{*}$ & -.09 & $.24^{* * *}$ & $.29^{* * *}$ & .17 & $.46^{* * *}$ & $.52^{* * *}$ & $.37^{* * *}$ & - & -.09 & -.10 & $-.20^{*}$ & .00 & -.13 & $-.19^{*}$ & $-.25^{*}$ \\
\hline Prosocial MR & -.04 & .01 & .12 & -.01 & $-.39^{* * *}$ & $-.43^{* * *}$ & $-.26^{* * *}$ & $-.35^{* * *}$ & $-.40^{* * *}$ & $-.17^{*}$ & - & $.67^{* * *}$ & $.50^{* * *}$ & $.43^{* * *}$ & .20 & $.29^{* *}$ & $.31^{* *}$ \\
\hline Prosocial FR & -.09 & .05 & .08 & -.03 & $-.36^{* * *}$ & $-.39^{* * *}$ & $-.24^{* * *}$ & $-.32^{* * *}$ & $-.40^{* * *}$ & -.15 & $.70^{* * *}$ & - & $.60^{* * *}$ & .19 & $.38^{* *}$ & .22 & $.26^{*}$ \\
\hline Prosocial CR & -.16 & $-.16^{*}$ & .11 & -.05 & $-.15^{*}$ & $-.23^{* *}$ & $-.26^{* * *}$ & -.10 & $-.20^{*}$ & $-.27^{* * *}$ & $.46^{* * *}$ & $.37^{* * *}$ & - & $.20^{*}$ & .20 & $.59 * * *$ & $.53^{* * *}$ \\
\hline Connection MR & -.09 & .00 & .11 & -.06 & $-.22^{* *}$ & -.01 & $-.16^{*}$ & -.14 & -.09 & -.03 & $.40^{* * *}$ & $.19^{*}$ & $.17^{*}$ & - & $.37^{* *}$ & $.31^{* * *}$ & $.41^{* * *}$ \\
\hline Connection FR & -.03 & -.03 & .07 & .05 & -.10 & $-.20^{*}$ & .03 & -.13 & $-.27^{* *}$ & .07 & $.26^{* *}$ & $.43^{* * * *}$ & .17 & .12 & - & $.27^{*}$ & $.39^{* *}$ \\
\hline Connection CRM & $-.27^{*}$ & -.04 & -.02 & -.07 & $-.37^{* * *}$ & $-.24^{* *}$ & $-.40^{* * *}$ & $-.27^{* * *}$ & $-.21^{*}$ & $-.32^{* * *}$ & $.37^{* * *}$ & $.34^{* * *}$ & $.48^{* * *}$ & $.20^{* *}$ & .17 & - & $.77^{* * *}$ \\
\hline Connection CRF & -.04 & -.04 & -.05 & -.01 & $-.27^{* * *}$ & $-.22^{*}$ & $-.33^{* * *}$ & $-.16^{*}$ & $-.20^{*}$ & $-.31^{* * *}$ & $.24^{* *}$ & $.34^{* * *}$ & $.41^{* * *}$ & .02 & $.29^{* *}$ & $.73^{* * *}$ & - \\
\hline
\end{tabular}

Boys are below the diagonal, girls are above.

For age-appropriate media, ( $0=$ age-appropriate, 1 = age-inappropriate).

$\mathrm{MR}=$ mother report; $\mathrm{FR}=$ father report; $\mathrm{CR}=$ child report; $\mathrm{CRM}=$ child report of mother; $\mathrm{CRM}=$ child report of father.

$\dagger p<.065$

$* p<.05$,

$* * p<.01$,

*** $p<.001$. 


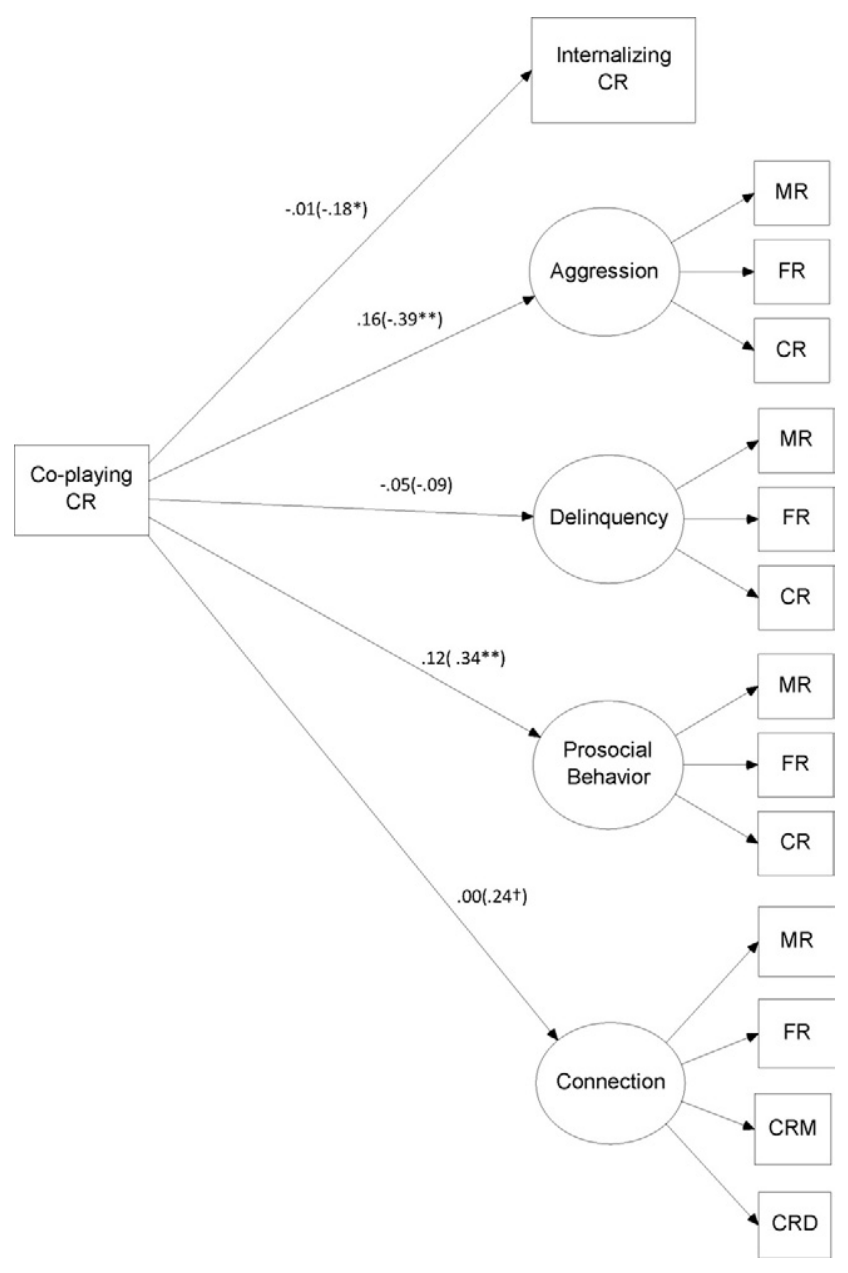

Figure 1. Co-Playing of video games related to adolescent outcomes and parentchild connection. Only standardized values are shown, boys' values before the parentheses, girls' inside the parentheses. Endogenous error correlations are not shown. $M R=$ mother report; $F R=$ father report; $C R=$ child report; $C R M(F)=$ child report of mother (father). $\chi 2(161)=227.1, p<.05$; CFI $=.961$, RMSEA $=$ $.035 . \dagger p<.052,{ }^{*} p<.05,{ }^{* *} p<.01,{ }^{* * *} p<.001$.

gender, except for the child's report of prosocial behavior. On the basis of all comparisons, this measurement model resulted in the best fit, $\chi 2(82)=117.9, p<.05, \mathrm{CFI}=.971$, RMSEA $=.039$, and all factor loadings were statistically significant at $\geq .48$.

\section{Structural model}

Next, a structural model was estimated modeling video game co-playing as a predictor of adolescents' internalizing problems, aggression, delinquency, prosocial behavior, and connection with parents (Figure 1). Adolescents' overall frequency of video game play and age-inappropriateness of games co-played were used as control variables. To test for group differences as a function of gender of the child, a series of multigroup models were estimated and compared using $\chi 2$ difference tests. Structural paths were examined by comparing a model where paths were free to vary across gender with one where paths were constrained to be equal across gender, constraining one path at a time, and then comparing the fully constrained model with the fully unconstrained model. Comparing the fully constrained model to the fully unconstrained model
Table 3

Unstandardized coefficients, standard errors, standardized coefficients, and significance levels for model in Figure $1(n=296)$

\begin{tabular}{|c|c|c|c|}
\hline Parameter estimate & Unstandardized & SE boys(girls) & Standardized \\
\hline \multicolumn{4}{|l|}{ Co-playing } \\
\hline Internalizing & $.002(-.048)$ & $.019(.021)$ & $.008\left(-.180^{*}\right)$ \\
\hline Aggression & $.062(-.154)$ & $.043(.067)$ & $.158\left(-.385^{* *}\right)$ \\
\hline Delinquency & $-.009(-.016)$ & $.013(.018)$ & $-.054(-.092)$ \\
\hline Prosocial behavior & $.069(.138)$ & $.046(.046)$ & $.122\left(.340^{* *}\right)$ \\
\hline Connection & $.001(.051)$ & $.013(.026)$ & $.004\left(.235^{\mathrm{a}}\right)$ \\
\hline \multicolumn{4}{|l|}{ Video game use } \\
\hline Co-playing & $.165(.042)$ & $.048(.101)$ & $.244^{* * *}(.041)$ \\
\hline Internalizing & $.018(.010)$ & $.013(.022)$ & $.093(.035)$ \\
\hline Aggression & $-.004(-.015)$ & $.029(.067)$ & $-.017(-.035)$ \\
\hline Delinquency & $.013(.014)$ & $.009(.019)$ & $.115(.078)$ \\
\hline Prosocial behavior & $-.014(.057)$ & $.031(.046)$ & $-.035(.131)$ \\
\hline Connection & $.005(.004)$ & $.009(.031)$ & $.053(.016)$ \\
\hline \multicolumn{4}{|c|}{ Age-inappropriate games } \\
\hline Internalizing & $-.020(.352)$ & $.066(.081)$ & $.030\left(.413^{* * *}\right)$ \\
\hline Aggression & $.088(.306)$ & $.152(.272)$ & $.094(.240)$ \\
\hline Delinquency & $.020(.103)$ & $.048(.074)$ & $.049(.182)$ \\
\hline Prosocial behavior & $-.075(-.164)$ & $.161(.177)$ & $-.055(-.127)$ \\
\hline Connection & $-.086(-.254)$ & $.053(.115)$ & $.285\left(-.364^{*}\right)$ \\
\hline $\begin{array}{l}{ }^{2}(139)=198.2, p<.05 \\
{ }^{a} p<.052 \\
{ }^{*} p<.05 \\
{ }^{*} p<.01 \\
{ }^{*} p<.001\end{array}$ & $=.964$, RMSEA $=$ & $=.036$ & \\
\hline
\end{tabular}

resulted in a significant decrease in model fit ( $\chi 2$ difference $(19)=$ $33.78, p<.05)$, and constraining one path at a time revealed that all structural paths differed as a function of gender, suggesting structural variance as a function of child gender. Thus, the best fitting structural model was a fully unconstrained model, allowing all paths to freely vary across gender $(\chi 2(161)=227.1, p<.05 ; \mathrm{CFI}=$ .961 , RMSEA $=.035)$. Results revealed that co-playing was not significantly related to any outcomes for boys, but was related to lower levels of internalizing problems and aggression and higher levels of prosocial behavior and connection (marginally) for girls. Although not shown in the figure for parsimony, adolescents' selfreported total video game use was positively related to co-playing for boys only, but was not significantly related to any of the outcome variables, whereas age-inappropriate games were not significantly related to any outcomes for boys, but were related to lower levels of connection and higher levels of internalizing problems for girls (Table 3 ).

\section{Discussion}

In summary, we found that although about $50 \%$ of children did report playing video games with their parents, mean levels were relatively low. Surprisingly, levels of co-playing did not differ for girls and boys, nor did they differ as a function of family structure, ethnicity, or income. At the bivariate level, time spent playing video games (especially inappropriate ones) was related to several negative effects. According to Nathanson [13], co-playing may amplify the negative effects of video games because parents inadvertently send the message that they endorse both time spent playing video games as well as the content. However, our analyses did not reveal widespread enhancement of negative effects. The only evidence of negative effects was for internalizing behavior, and this was only for girls who played age-inappropriate games with their parents.

Instead, our analyses revealed that co-playing shows favorable effects for girls, but seems to have little effect for boys. Specifically, 
co-playing was marginally associated with higher levels of parentchild connectedness for girls, particularly when playing ageappropriate games. When parents play video games with their daughters, they may be sending a myriad of messages. First, parents may show that they are willing to engage in an activity that is important to daughters. Second, playing video games can represent quality time between a daughter and a parent, especially when such play involves conversation between parent-child. Interestingly, heightened parent-child connection was not found for girls who played age-inappropriate games with their parents. It is possible that exposure to such inappropriate content may influence both parent and daughter mood and ability to respond to each other. Additionally, such games are often very intense and may interfere with conversation or interaction that may lead to heightened levels of connection.

Girls who played video games with their parents also showed many important behavioral outcomes. Specifically, we found an association between co-playing of video games and lowered internalizing (e.g., depression/anxiety) and aggressive behavior. Furthermore, girls who co-played with their parents reported more prosocial behavior toward family members, which may be a function of higher relationship quality between daughters and parents who co-play [20]. These findings certainly confirm parents' own views of co-playing [7,8], who believe that co-playing would result in positive social and emotional outcomes. Furthermore, they allay fears that co-playing video games result in negative outcomes, at least for girls [14]. In fact, it seems that the time parents spend playing video games with daughters can have positive outcomes, both for the daughter and for the relationship between child and parent. Conversely, co-playing was not associated with any outcome (either positive or negative) for boys. We offer a few speculative ideas for why this might be the case. First, boys tend to play video games more often than girls, as was found in the current study. However, parents report spending about the same amount of time co-playing with boys and girls. Therefore, boys most likely spend the majority of time playing video games without a parent present, making any effects of co-playing comparatively smaller for boys as compared with girls. Furthermore, other research $[2,3]$ has shown that boys tend to play more violent games than girls. We found that parents are more likely to play age-inappropriate (and most likely more violent) games with their sons than with their daughters. Boys may already be playing such games, and parents might assume that co-playing the games is a successful mediation strategy and mitigates any negative effects of playing video games. However, our study suggests that co-playing was not a particularly useful mediation strategy for boys; in fact, co-playing video-games (even age-appropriate ones) showed no effects for boys. Other mediation strategies, including restrictive (e.g., setting rules on time and content) and active (e.g., discussion on content) forms, may prove to be more fruitful in mediating video game play for boys.

Although this study showed some positive associations for girls who play video games with their parents, it should be noted that the data were cross-sectional and longitudinal studies are needed to confirm long-term effects of co-playing for both boys and girls. Additionally, the data are correlational and cannot be interpreted in terms of causality. We were also unable to determine who among the two parents, the child reported as being their co-playing partner (or whether the whole family was playing). It is possible that the frequency and effect of co-playing differs as a function of the parents' gender, and future research should examine this possibility. It should also be noted that the way by which we measured co-playing could be expanded in future research, specifically to examine the exact amount of time spent in co-playing as opposed to how frequently per week the behavior occurs.

Despite these limitations, to our knowledge, this study is the first to show positive associations for girls who play video games with their parents. In addition, results were based on measures from multiple reporters (parents and child) for all variables, potentially representing a more complete view of behavioral outcomes. Co-playing was not only associated with less negative and more positive outcomes for girls themselves, but girls and parents both reported feeling more connected with each other also, especially when playing age-appropriate games. As video games become more popular in the years to come, co-playing (at least with girls) may be one way to stay involved with adolescent activities and to negate at least some of the negative effects of playing video games.

\section{Acknowledgments}

The authors thank the Family Studies Center at BYU, the School of Family Life, and the College of Family Home and Social Science at BYU, and recognize the generous support of the many private donors who provided support for this project. The authors also thank those families who were willing to spend valuable hours with the research team in interviews, and the many students who assisted in conducting the interviews.

\section{References}

[1] Kaiser Family Foundation. Generation M2: Media in the lives of 8 to 18-year olds. Menlo Park, CA: Kaiser Family Foundation, 2010.

[2] Buchman DD, Funk JB. Video and computer games in the 90s: Children's time commitment and game preference. Child Today 1996;24:12-5.

[3] Funk JB. Video games. In: Strasbuger VC, Wilson BJ, Jordan AB, eds. Children, Adolescents, and the Media. Thousand Oaks, CA: Sage, 2009:435-70.

[4] Anderson CA, Gentile DA, Buckley KA. Violent video game effects on children and adolescents: Theory, research, and public policy. New York, NY: Oxford University Press, 2007.

[5] Gentile DA. Pathological video game use among youth 8 to 18: A national study. Psychol Sci 2009;20:594-602.

[6] Kutner LA, Olson CK, Warner DE, Hertzog SM. Parents' and sons' perspective on video game play. J Adolesc Res 2008;23:76-96.

[7] Nikken P, Jansz J. Parental mediation of children's videogame playing: A comparison of the reports by parents and children. Learn Media Technol 2006;31:181-202.

[8] Nikken P, Jansz J, Schouwstra S. Parents' interest in video game ratings and content descriptors in relation to game mediation. Eur J Commun 2007;22:315-36.

[9] Brown JD, Cantor J. An agenda for research on youth and the media. J Adolesc Health 2000;27:2-7.

[10] Rice ML, Huston AC, Tuglio R, Wright J. Words from Sesame Street: Learning vocabulary while viewing. Dev Psychol 1990;26:421-8.

[11] Wilson BJ, Weiss AJ. The effects of sibling coviewing on preschoolers' reactions to suspenseful movie scenes. Commun Res 1993;20:214-48.

[12] Nathanson AI. Parent and child perspective on the presence and meaning of parental television mediation. J Broadcasting Electron Media 2001;45:210-20.

[13] Nathanson AI. The unintended effects of parental mediation of television on adolescents. Media Psychol 2002;4:207-30.

[14] Padilla-Walker LM, Harper JM, Bean RA. Pathways to parental knowledge: The role of family process and family structure. J Early Adolesc (in press).

[15] Barber BK, Stolz HE, Olsen JA. Parental support, psychological control, and behavioral control: Assessing relevance across time, culture, and method. Monogr Soc Res Child Dev 2005;70:1-137.

[16] Weinberger D, Schwartz G, Davidson R. Low-anxious, high-anxious, and repressive coping styles: Psychometric patterns and behavioral and physiological responses to stress. J Abnorm Psychol 1979;88:369 - 80.

[17] Peterson C, Seligman MEP. Character strengths and virtues: A handbook and classification. Washington, DC: Oxford University Press, 2004.

[18] Robinson CC, Mandleco B, Olsen SF, Hart CH. The parenting styles and dimensions questionnaire (PSQD). In: Perlmutter BF, Touliatos J, Holden GW, eds. Handbook of Family Measurement Techniques: Instruments and Index, Vol. 3. Thousand Oaks, CA: Sage, 2001:319-21.

[19] Arbuckle JL. Amos 16.0 user's guide. Chicago, IL: SPSS, Amos Development Corporation, 2007

[20] Padilla-Walker LM, Christensen KJ. Empathy and self-regulation as mediators between parenting and adolescents' prosocial behaviors toward strangers, friends, and family. J Res Adolesc (in press). 